\title{
ANALYSIS OF HARMONIC VIBRATION OF CABLE-STAYED FOOTBRIDGE UNDER THE INFLUENCE OF CHANGES OF THE CABLES TENSION
}

\author{
WOJCIECH PAKOS \\ Wrocław University of Technology, Wybrzeże Wyspiańskiego 27, 50-370 Wrocław, Poland. \\ E-mail: wojciech.pakos@pwr.edu.pl
}

\begin{abstract}
The paper presents numerical analysis of harmonically excited vibration of a cable-stayed footbridge caused by a load function simulating crouching (squats) while changing the static tension in chosen cables. The intentional synchronized motion (e.g., squats) of a single person or group of persons on the footbridge with a frequency close to the natural frequency of the structure may lead to the resonant vibrations with large amplitudes. The appropriate tension changes in some cables cause detuning of resonance on account of stiffness changes of structures and hence detuning in the natural frequency that is close to the excitation frequency. The research was carried out on a 3D computer model of a real structure - a cable-stayed steel footbridge in Leśnica, a quarter of Wrocław, Poland, with the help of standard computer software based on FEM COSMOS/M System.
\end{abstract}

Key words: cable-stayed footbridge, FEM model, harmonic vibration, vibration reduction

\section{INTRODUCTION}

The paper presents theoretical (numerical) analysis of harmonically excited vibration of a cable-stayed footbridge under the influence of changes in the static tension in chosen cables. The appropriate tension changes cause changes of stiffness of structures and hence changes in the natural frequency that is close to the excitation frequency. As a consequence of these changes the harmonic forced vibration amplitudes are reduced significantly because the resonant state becomes detuned. In this paper, the excitation is described by the formula specified by Żółtowski [1], i.e., load function simulating crouching (squats). Such an excitation is sometimes caused intentionally by groups of people and may lead to a particularly dangerous phenomenon, i.e., the resonant vibrations with large amplitudes.

In papers [2], [3], eigenproblem sensitivity analysis formulated for the structure according to the second order theory has been used in order to establish which combinations of tensions in cables lead to the fastest change in the values of chosen natural frequencies. In paper [2], the effectiveness of this method on a laboratory model of a steel cable-stayed footbridge (scale 1:10) was tested. Papers [2], [4] present also how such changes of the tension in chosen cables that are enough to obtain a significant effect of the vibration reduction, influence the value of displacements and value of internal forces for some of the structure elements (main girder, pylon) and whether these changes contribute to exceeding the levels of Serviceability Limit State (SLS) and Ultimate Limit State (ULS) for the structure.

The methods of active vibration reduction in cable-stayed bridges were investigated both experimentally and theoretically in the last three decades by some authors, for example, Achkire [5], Preumont and Achkire [6], Bossens and Preumont [7], Warnitchai, Fujino et al. [8], Fujino and Susumpow [9], Susumpow and Fujino [10]. The solutions of active methods of reducing vibration described in the above-mentioned papers have not yet been implemented in real bridge structures.

\section{DESCRIPTION OF A FEM MODEL OF THE CABLE-STAYED FOOTBRIDGE}

The theoretical analysis was carried out with the use of a FEM numerical model of a footbridge closely corresponding to the real structure, i.e., a cable-stayed steel footbridge in Leśnica, a quarter of Wrocław, a city in Poland (Fig. 1). Numerical analyses were 


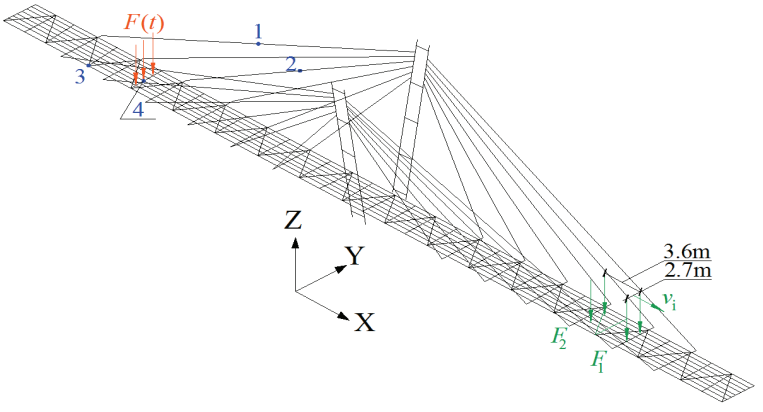

a)

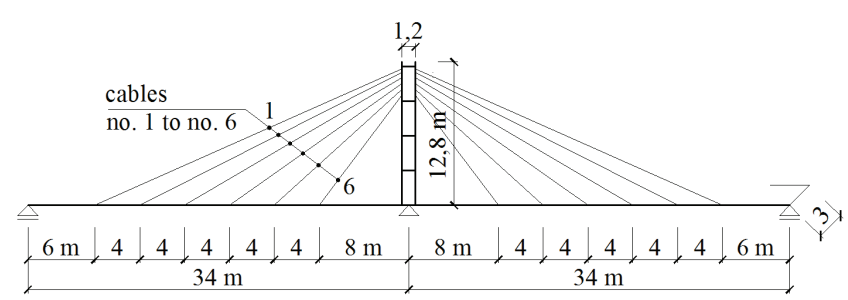

b)

Fig. 1. (a) 3D FEM model of cable-stayed footbridge and selected nodes, (b) the geometry of the system

performed with the help of a standard computer FEM software, i.e., COSMOS/M System. The structure has been modeled as three-dimensional structure with the use of beam elements and shell elements.

\subsection{MATERIAL AND GEOMETRICAL DATA OF THE CABLE-STAYED FOOTBRIDGE}

The cable-stayed footbridge has been designed as a two-span footbridge with a length of $34.0 \mathrm{~m}$ of each span. The deck and pylon were made of steel. The cable-stayed footbridge has one pylon about $12.80 \mathrm{~m}$ high, made of steel pipes. The deck structure consists of two tubes $\varnothing 323.9 / 12.5$ with axial spacing of $3.00 \mathrm{~m}$ that are connected by cross-beams made from I-beams HEB140, spacing $2.00 \mathrm{~m}$. On the cross beams there are mounted stringers HEB100 with axial spacing from 400 to $500 \mathrm{~mm}$ covered with a $12 \mathrm{~mm}$ thick metal sheet. All the connections of the girder are made as welded ones. The superstructure deck is supported by one- and two-way sliding bearings on both abutments and by fixed bearings on a pillar. The pylon is located in the center of the deck and is attached to a reinforced concrete pillar, rigidly using steel anchors. The deck is supported from a pylon by 24 pairs of high tensile cable made of $2 \mathrm{~T} 15(2 \times 7 \varnothing 5 \mathrm{~mm})$ ropes produced by Freyssinet Company. Active anchorages of the cables are placed at the deck level, whereas passive ones are located in the pylon. The geometrical and mechanical characteristics of elements of the span are given in Table 1. Due to taking into account the handrail elements, stiffness of the main girders for numerical modelling was assumed as equal to $I_{x}=90000 \mathrm{~cm}^{4}$. The mechanical characteristics of the cables: guaranteed breaking load $N_{\text {cr }}=530 \mathrm{kN}$, grade $f_{y k}=1770 \mathrm{MPa}$, Young's modulus $E=195 \mathrm{GPa}$, cross section $A=300 \mathrm{~mm}^{2}$. Material and geometrical data were assumed according to papers [2], [11], [12].

\subsection{NON-LINEAR EQUATION OF MOTION}

The numerical analysis used the well-known finite element method (FEM), where the real system is described using a discrete system, i.e., a finite number of

Table 1. The geometrical characteristics of the span elements

\begin{tabular}{|c|c|c|c|c|c|c|c|}
\hline & Element & $\begin{array}{c}A \\
{\left[\mathrm{~cm}^{2}\right]}\end{array}$ & $\begin{array}{c}I_{x} \\
{\left[\mathrm{~cm}^{4}\right]}\end{array}$ & $\begin{array}{c}I_{y} \\
{\left[\mathrm{~cm}^{4}\right]}\end{array}$ & $\begin{array}{c}W_{x} \\
{\left[\mathrm{~cm}^{3}\right]}\end{array}$ & $\begin{array}{c}W_{y} \\
{\left[\mathrm{~cm}^{3}\right]}\end{array}$ & $\begin{array}{c}q \\
{[\mathrm{~kg} / \mathrm{m}]}\end{array}$ \\
\hline \multirow{5}{*}{$\begin{array}{l}\text { Uै } \\
\mathscr{D} \\
\end{array}$} & Main girder - a tube $\varnothing 323.9 / 12.5$ & 122.3 & 14846.5 & 14846.5 & \multicolumn{2}{|c|}{916.7} & 96.0 \\
\hline & Stringers - HEB 100 & 26.0 & 450.0 & 167.0 & 90.0 & 33,4 & 20.41 \\
\hline & Bracing - C-rail 100 & 13.5 & 206.0 & 29.3 & 41.2 & 8.49 & 10.6 \\
\hline & Cross beams - HEB 140 & 43.0 & 1510.0 & 550.0 & 215.7 & 78.6 & 33.8 \\
\hline & $\begin{array}{l}\text { Anchorages support cables } \\
\text { - a tube } \varnothing 219.1 / 12.5\end{array}$ & 81.1 & \multicolumn{2}{|c|}{4344.6} & \multicolumn{2}{|c|}{396.6} & 63.7 \\
\hline \multirow{3}{*}{$\frac{0}{2}$} & Pylon - a tube $\varnothing 406.4 / 20.0$ & 242.8 & \multicolumn{2}{|c|}{45432.1} & \multicolumn{2}{|c|}{2235.8} & 190.6 \\
\hline & Longitudinal strut - a tube $\varnothing 355.6 / 20$ & 210.9 & \multicolumn{2}{|c|}{29791.7} & \multicolumn{2}{|c|}{1675.57} & 165.5 \\
\hline & Transverse strut - a tube $\varnothing 273 / 20$ & 159.0 & \multicolumn{2}{|c|}{12798.4} & \multicolumn{2}{|c|}{937.6} & 124.8 \\
\hline
\end{tabular}

$A$ - Cross section, $\left[\mathrm{cm}^{2}\right] ; I_{x}, I_{y}-$ moment of inertia, $\left[\mathrm{cm}^{4}\right] ; W_{x}, W_{y}-$ section modulus, $\left[\mathrm{cm}^{3}\right] ; q-$ dead weight, $\left[\mathrm{kg} / \mathrm{m}^{3}\right]$. 
differential equations. The non-linear equation of motion may be presented in the well-known matrix form [13]

$$
\mathbf{B} \ddot{\mathrm{q}}+\mathbf{C} \dot{\mathrm{q}}+\left[\mathbf{K}_{\mathrm{E}}+\mathbf{K}_{\mathrm{G}}+\mathbf{K}_{\mathrm{U}}\right] \mathbf{q}=\mathbf{F}(t)
$$

where $\mathbf{B}$ is the inertia matrix; $\mathbf{C}$ is the damping matrix; $\mathbf{K}_{\mathrm{E}}$ is the elastic stiffness matrix (constitutive); $\mathbf{K}_{\mathrm{G}}$ is the geometrical matrix, sometimes called the initial tension matrix; $\mathbf{K}_{\mathrm{U}}$ is the matrix of initial displacement (rotation), also called large displacement or large deformation matrix. All matrices have the dimension $n \times n$ where $n$ is the number of degrees of freedom of the system. $\mathbf{F}(t)$ is a vector of the generalized excitation forces, while $\mathbf{q}$ is the vector of generalized coordinates which describe node displacements.

The nonlinear equation (1) describes the forced vibration in the cases of large displacements as well as takes into account the influence of the displacement on the structure strain, i.e. the geometric nonlinearity [13], [14]. Equation (1) makes it possible to take into consideration the influence of the normal forces, especially the cable tension, on bending stiffness. The equation also makes it possible to explicitly determine the dependence of the stiffness matrix describing the elastic stiffness of the system on the axis force values - and, by extension, on the cable tension values.

\subsection{FOOTBRIDGE NATURAL FREQUENCIES}

Table 2 presents the footbridge natural frequencies that correspond to the eigenforms in which the platform and the pylon displacement was dominant. The natural frequencies have been obtained on the basis of numerical analysis of the COSMOS/M FEM model. The COSMOS/M numerical FEM model has also been used to calculate the natural frequencies $f_{c . w p}, f_{c . z p}$ that correspond to the eigenforms in which the cable displacement was dominant. These results are presented in Table 3.

Table 2. Natural frequencies of the deck and pylon calculated in COSMOS/M

\begin{tabular}{|c|l|c|}
\hline $\begin{array}{c}\text { Form } \\
\text { number }\end{array}$ & \multicolumn{1}{|c|}{$\begin{array}{c}\text { Form } \\
\text { description }\end{array}$} & $\begin{array}{c}\text { Natural } \\
\text { frequency } \\
f[\mathrm{~Hz}]\end{array}$ \\
\hline 1 & deck -1 st bending antisymmetric & 1.74988 \\
\hline 2 & deck -1 st bending symmetric & 2.82876 \\
\hline 3 & pylon -1 st plane bending & 2.96694 \\
\hline 4 & deck -2 nd bending antisymmetric & 4.58009 \\
\hline 5 & deck - 2nd bending symmetric & 5.32533 \\
\hline 6 & deck - torsion & 6.11629 \\
\hline
\end{tabular}

Table 3. Natural frequencies of cables calculated in COSMOS/M.

\begin{tabular}{|c|c|c|c|c|}
\hline $\begin{array}{c}\text { Cable } \\
\text { symbol }\end{array}$ & $\begin{array}{c}f_{\text {I.wp }} \\
{[\mathrm{Hz}]}\end{array}$ & $\begin{array}{c}f_{\text {I.zp }} \\
{[\mathrm{Hz}]}\end{array}$ & $\begin{array}{c}f_{\text {c.wp }} \\
{[\mathrm{Hz}]}\end{array}$ & $\begin{array}{c}f_{\text {c.zp }} \\
{[\mathrm{Hz}]}\end{array}$ \\
\hline $\mathrm{C}_{1}$ & 2.3893 & 2.3883 & 2.4112 & 2.4108 \\
\hline $\mathrm{C}_{2}$ & 2.6931 & 2.6678 & 2.6982 & 2.6972 \\
\hline $\mathrm{C}_{3}$ & 2.9493 & 2.9191 & 2.9782 & 2.9611 \\
\hline $\mathrm{C}_{4}$ & 3.4962 & 3.4728 & 3.6338 & 3.6306 \\
\hline $\mathrm{C}_{5}$ & 4.2953 & 4.2741 & 4.3854 & 4.3705 \\
\hline $\mathrm{C}_{6}$ & 4.7865 & 4.7562 & 4.9434 & 4.9434 \\
\hline
\end{tabular}

Table 3 also presents natural frequencies $f_{\text {I.wp }}, f_{\text {I.zp }}$ obtained with the use of Irvine's formulas (2) and (3). These formulas describe the natural frequencies of the cable considered apart from the structure, where $m$ is the cable mass per one unit of its length and $N$ is the cable tension.

Irvin proposed formula (2) for calculating the natural frequencies for the eigenforms in the plane of the sag $(w p)$ where $\bar{\omega}_{n}$ is the value of non-dimensional natural frequency

$$
\begin{gathered}
f_{\text {I.wp }}=\frac{\omega_{n}}{2 \pi}=\frac{\bar{\omega}_{n}}{2 \pi L} \sqrt{\frac{N}{m}}, \quad n=1,2,3, \ldots, \\
\tan \left(\frac{\bar{\omega}_{n}}{2}\right)=\frac{\bar{\omega}_{n}}{2}-\frac{4}{\lambda^{2}}\left(\frac{\bar{\omega}_{n}}{2}\right)^{3}
\end{gathered}
$$

where $\lambda^{2}$ is Irvine's parameter. Irvin proposed formula (3) for calculating the natural frequencies for the eigenforms out-of-plane of the sag $(z p)$

$$
f_{I . z p}=\frac{\omega_{n}}{2 \pi}=\frac{n}{2 L} \sqrt{\frac{N}{m}}, \quad n=1,2,3, \ldots
$$

A comparison between the results in Table 3 reveals a very high accordance between numerical solutions obtained from the FEM model and the analytical results obtained from Irvine's formula.

\subsection{SELECTION OF DAMPING MODEL IN NUMERICAL ANALYSIS}

For the purposes of numerical solutions of vibration of the FEM footbridge model in which damping is taken into account, the parameters of four damping models were determined. The following models were analysed: mass, Voigt-Kelvin, Rayleigh, and modal damping. The example assumes the dimensionless parameter specified with the use of formula $\xi_{i}=0.027 \cdot f_{i}^{-0.9}$ given by Bachmann and others in paper [15]. The dimensionless parameter $\xi$, called the damping ratio, is the ratio of viscous damping to critical damping and is re- 
lated to the dimensionless damping coefficient by formula $\gamma=2 \xi$. The damping ratio corresponding to the first bending eigenform of the deck with a natural frequency $f_{1}=1.74988 \mathrm{~Hz}$ was calculated to be $\xi=0.0163$. The dimensionless damping coefficient is $\gamma=2 \xi=0.0326$. The value of dimensionless parameter calculated with the use of the above-mentioned approximated formula is comparable to the value of $\xi=0.012$ obtained from experimental tests and presented by authors [11] and [12]. On the basis of the calculated values of dimensionless parameter $\xi$, parameters $\alpha$ and $\beta$ were determined. These parameters were used to construct the damping matrix $\mathbf{C}$ in the equation of motion of the system (1). In accordance with the procedures of the COSMOS/M, the damping matrix was expressed by formula $\mathbf{C}=\alpha \cdot \mathbf{B}+\beta \cdot \mathbf{K}$ [16].

The value of parameter $\alpha$ of the mass damping model $\mathbf{C}=\alpha \cdot \mathbf{B}$, corresponding to the first bending eigenform of the deck with a natural frequency of $f_{1}=$ $1.74988 \mathrm{~Hz}$ equals $\alpha=\gamma \cdot \omega_{i}=\gamma 2 \pi f_{1}=0.359 \mathrm{~s}^{-1}$, where $\gamma=2 \xi=0.0326$. The value of parameter $\beta$ of the Voigt-Kelvin model $\mathbf{C}=\beta \cdot \mathbf{K}$ for the same frequency $f_{1}=1.74988 \mathrm{~Hz}$ equals $\beta=\gamma / \omega_{1}=\gamma / 1 \pi f_{1}=0.000115 \mathrm{~s}$. The values of the parameters $\alpha$ and $\beta$ in the case of the Rayleigh model $\mathbf{C}=\alpha \cdot \mathbf{B}+\beta \cdot \mathbf{K}$ were obtained, where a set of two equations was solved, i.e., $\gamma_{i}=\alpha / \omega_{i}+\beta \omega_{i}$ and $\gamma_{j}=\alpha / \omega_{j}+\beta \omega_{j}$, in which it was assumed that the coefficients $\gamma_{1}=\gamma_{2}=\gamma=0.0326$ are equal for two chosen natural frequencies, i.e., natural frequency $f_{1}=$ $1.74988 \mathrm{~Hz}$ corresponding to the first bending antisymmetric eigenform of the deck, and natural frequency $f_{2}=4.5885 \mathrm{~Hz}$ corresponding to the second bending antisymmetric eigenform of the deck. The following parameters of the Rayleigh model were obtained: $\alpha=0.2214 \mathrm{~s}^{-1}$ and $\beta=0.0011 \mathrm{~s}$.

In addition, modal damping, where $\xi_{i}$ is the modal damping ratio of the $i$-th mode, was considered. The number of dimensionless parameters is such as the number of degrees of freedom and $\xi_{i}$ were specified with the use of the above-mentioned formula $\xi_{i}=$ $0.027 \cdot f_{i}^{-0.9}$.

In order to choose the appropriate variant of the damping model, fragments of time histories of the displacement of chosen points of the structure were compared. For this purpose, the excitation was mod-
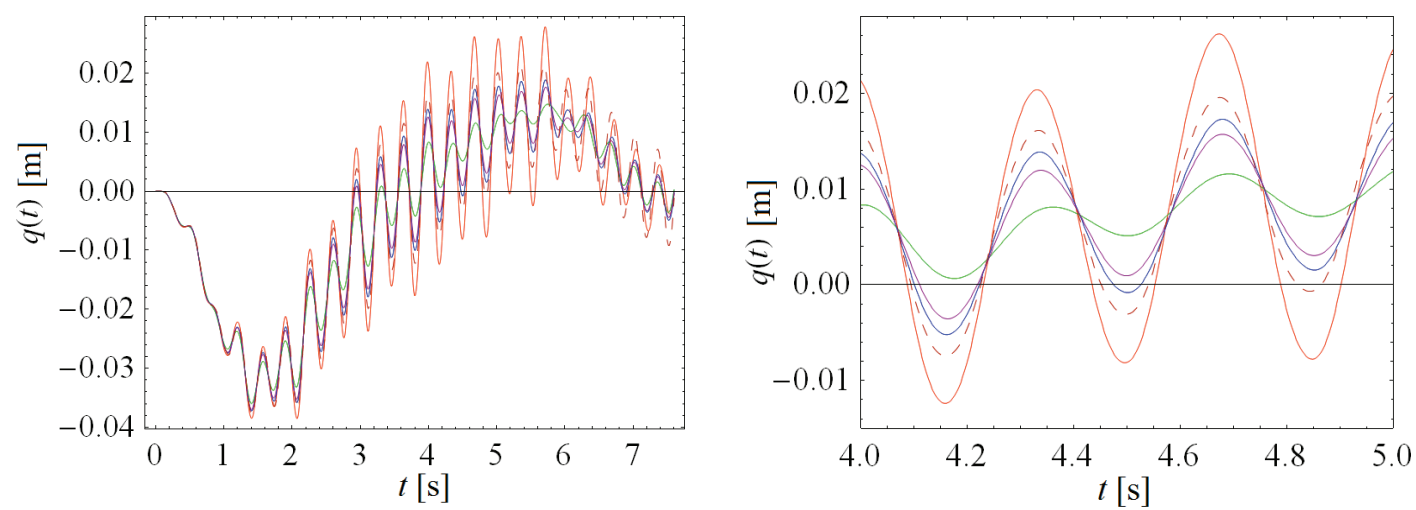

Fig. 2. Vibration of vertical displacement of node No. 2, at a constant speed $v=10 \mathrm{~m} / \mathrm{s}$ of the vehicle, for damping models: — without damping, - mass, - Voigt-Kelvin, — Rayleigh, - - modal damping
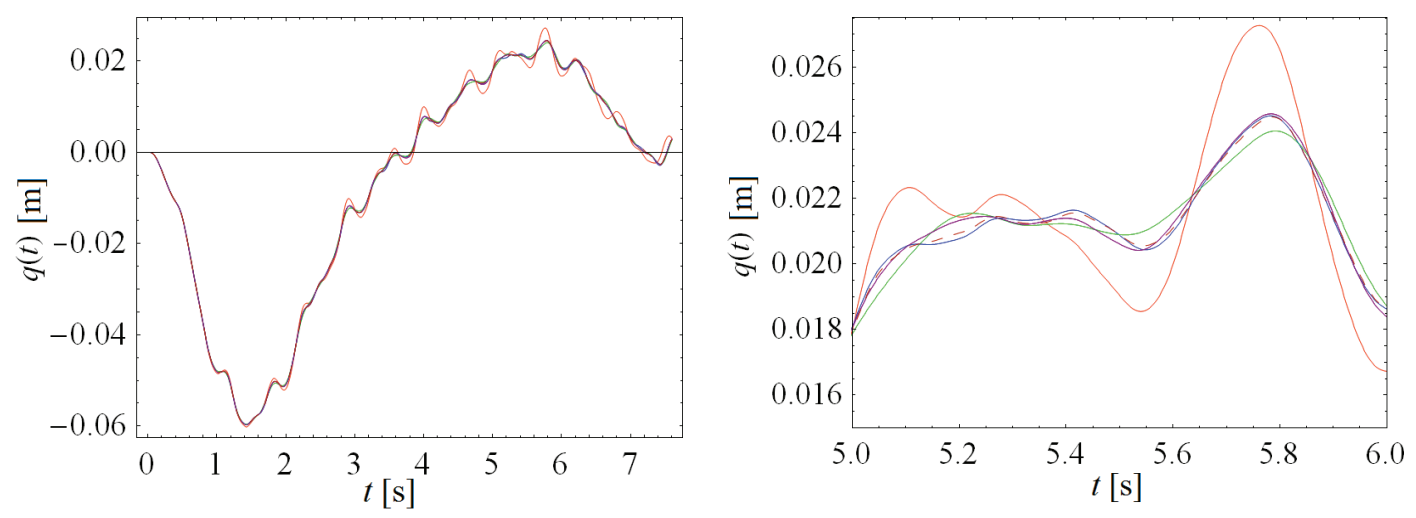

Fig. 3. Vibration of vertical displacement of node No. 3, at a constant speed $v=10 \mathrm{~m} / \mathrm{s}$ of the vehicle, for damping models: - without damping, - mass, - Voigt-Kelvin, — Rayleigh, - - modal damping 
eled by series of movable concentrated forces, as a moving vehicle. As in the case of bridges for driving and pedestrians load class E was adopted [17]. A total weight of vehicle is $150 \mathrm{kN}$ and focuses on individual axles $F_{1}=50 \mathrm{kN}$ and $F_{2}=100 \mathrm{kN}$. The wheelbase of a vehicle equals $2.7 \mathrm{~m}$ and $3.6 \mathrm{~m}$ [17]. The calculations assuming constant speed of the vehicle were performed. Three values of speed: $v_{1}=5 \mathrm{~m} / \mathrm{s}$ $=18 \mathrm{~km} / \mathrm{h}, v_{2}=10 \mathrm{~m} / \mathrm{s}=36 \mathrm{~km} / \mathrm{s}$, and $v_{3}=20 \mathrm{~m} / \mathrm{s}$ $=72 \mathrm{~km} / \mathrm{h}$ were taken into consideration.

Figures 2 and 3 show the time histories of the vibration displacement for the four damping models described above, determined numerically using the system COSMOS/M. Those are time histories of the vibration displacement of chosen points of the structure, i.e., No. 2 and No. 3 (Fig. 1), forced by the vehicle while moving at a constant speed $v_{2}=10 \mathrm{~m} / \mathrm{s}$. Figures 2 and 3 show the time histories of the vibration displacement from the arrival of the vehicle on the bridge until it leaves the bridge. In order to enable a more accurate interpretation of the influence of damping models, the graph also shows fragments of the time histories of the vibration narrowly focused to a few oscillations.

In the case of the solution illustrated in Fig. 2, assumption of the mass model and modal damping model leads to the emergence of similar vibration cycles as in a system without damping. On the basis of numerical analysis, it was found that the mass damping
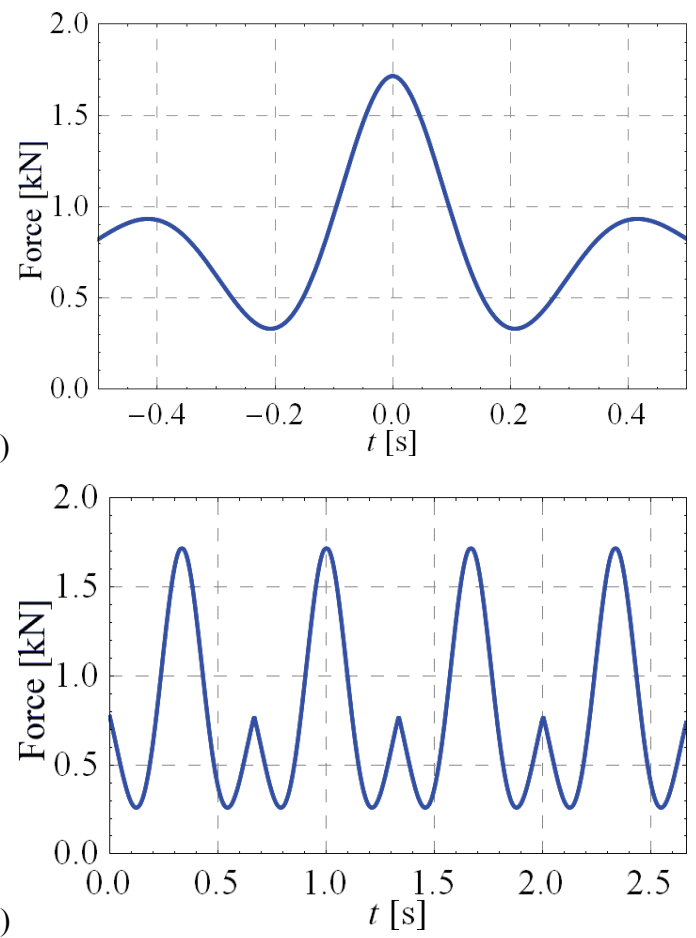

(b)
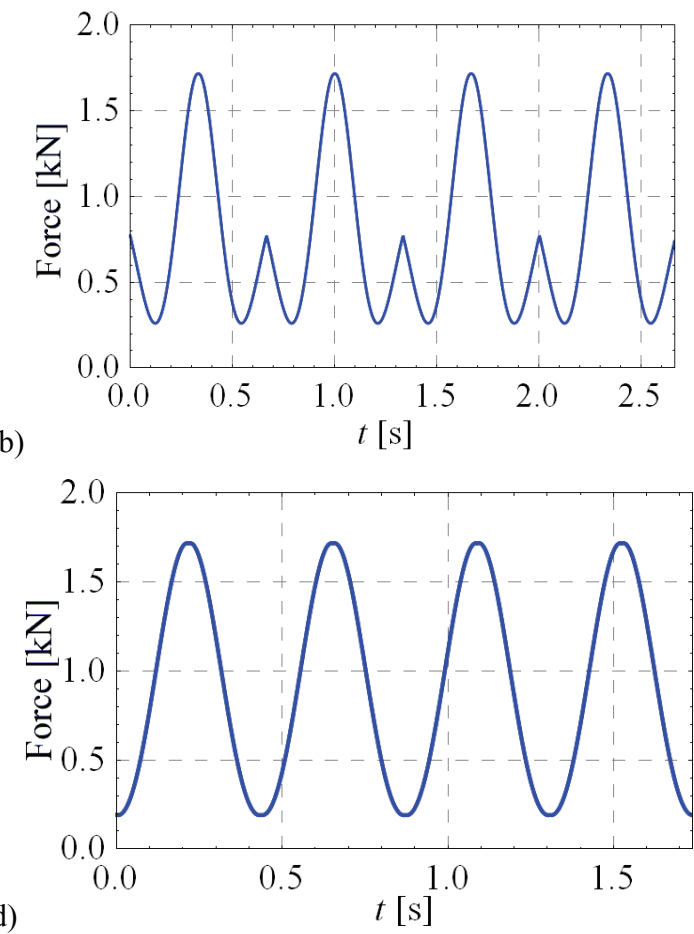

Fig. 4. The impact of one person by harmonic forcing with different frequencies $f[\mathrm{~Hz}]$ :

(a) single impulse (squat), (b) $f=1.0 \mathrm{~Hz}$ (c) $f=1.5 \mathrm{~Hz} \mathrm{~d}$ ) $f=2.3 \mathrm{~Hz}$ on the structure (own calculations based on [1]) 
(i.e., resonance), which causes excessive vibration. Such excitation is often caused intentionally by groups of people, out of curiosity or, sometimes, as an act of vandalism. This is a particularly dangerous phenomenon as it leads to resonant vibrations with large amplitudes.

Żółtowski in paper [1] proposed a theoretical model of the load, on the basis of empirical studies conducted by himself on the impact of humans performing squats on the fixed and vibrating platform in the frequencies band $1.0-2.4 \mathrm{~Hz}$ with a maximum amplitude displacement of $3 \mathrm{~mm}$. Żółtowski [1] described the harmonic function (4) of the intentional excitation of the structures by squats. This function depends only on the frequency of the excitation $f_{p}$ equal to the natural frequency of the structures and takes into account the damping.

$$
F(t)=0.75\left[1.33 \cdot \cos (4,8 \pi|t|-0.25) e^{-4|t| \sqrt{\frac{1}{f_{p}}}}+1\right]
$$

for $t \in\left(-\frac{1}{f_{p}}, \frac{1}{f_{p}}\right), f_{p} \in(0 ; 2,4) \mathrm{Hz}$.

Figure 4a presents, on the basis of equation (4), the impact of a single squat on the structure. Figures $4 b, c, d$

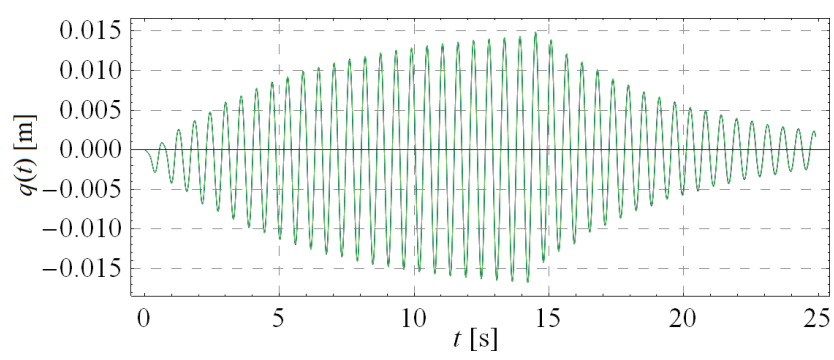

Fig. 5. Vertical displacements $q_{\mathrm{z}}(t)$ [m] for node No. 4 by harmonic forcing with frequency $f=1.7489 \mathrm{~Hz}$, for different effort cables No. 1: $-8.92 \% ;-10.15 \%$; $-13.04 \%$

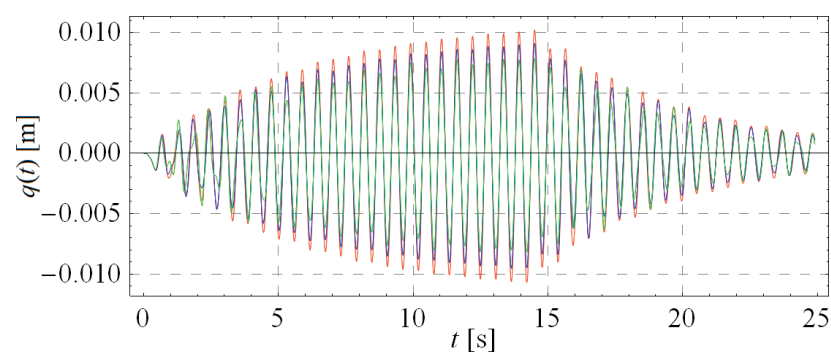

Fig. 6. Vertical displacements $q_{\mathrm{z}}(t)$ [m] for node No. 1 by harmonic forcing with frequency $f=1.7489 \mathrm{~Hz}$, for different effort cables No. 1: $-8.92 \%$; $-10.15 \%$; $-13.04 \%$ present the impact of one person at different frequencies of the excitation on the structure.

Higher number of people increases the vibration amplitude and in accordance with paper [1] is a multiple of formula (4) $F_{M}(t)=M \cdot F(t)$, where: $M$ - number of people, $F(t)$ - formula (4) simulating the intentional excitation of the structures by squats. This assumption is possible when the group of people achieved full synchronization of squats.

\subsection{FORCED VIBRATION AMPLITUDES AT DIFFERENT CABLES TENSION}

Two cases of excitation caused by three persons performing squats were considered. The first case - excitation of a bridge at the resonant frequency $f=1.7489 \mathrm{~Hz}$, lasting for 14.375 seconds and the second case - excitation at the resonant frequency equal to the natural frequency of a stay cable No. 1, i.e., $f=2.4112 \mathrm{~Hz}$, lasting for 8.3 seconds. Figures $5-8$ show the time histories of the vibration displacement for the different tendons tension of cables No. 1. The first condition: the initial state of tendons effort is $8.92 \%$. The initial state means that stay cable forces were chosen in such a way as to settle the deck's

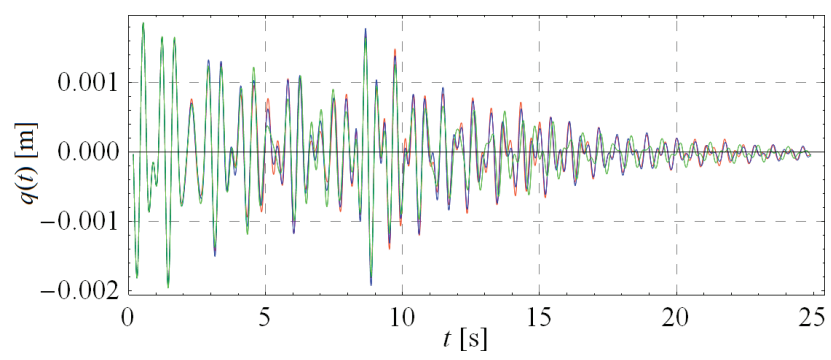

Fig. 7. Vertical displacements $q_{\mathrm{z}}(t)[\mathrm{m}]$ for node No. 4 by harmonic forcing with frequency $f=2.4112 \mathrm{~Hz}$ : for different effort cables No. $1:-8.92 \% ;-10.15 \% ;-13.04 \%$

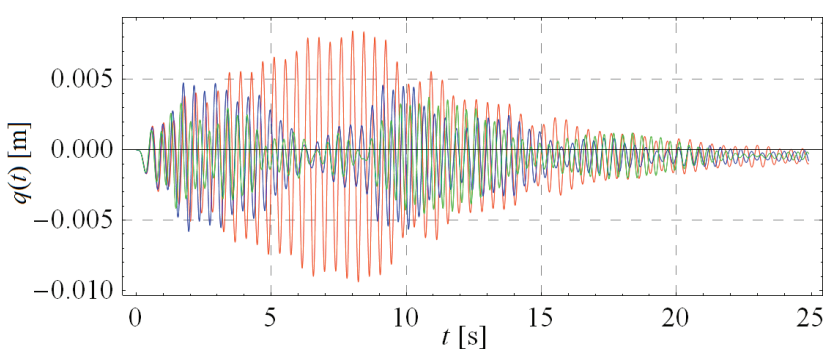

Fig. 8. Vertical displacements $q_{\mathrm{z}}(t)[\mathrm{m}]$ for node No. 1 by harmonic forcing with frequency $f=2.4112 \mathrm{~Hz}$, for different effort cables No. 1 : $-8.92 \%$; $10.15 \%$; $-13.04 \%$ 
Table 4. The results of numerical analysis at excitation caused by three people performing squats

\begin{tabular}{|c|c|c|c|c|c|}
\hline $\begin{array}{l}\text { Node } \\
\text { number }\end{array}$ & $\begin{array}{c}\text { Effort } \\
\text { cables No. } 1 \\
{\left[\sigma_{\mathrm{i}}=N_{\mathrm{i}} / P_{\mathrm{k}}\right]}\end{array}$ & $\begin{array}{c}\text { Excitation } \\
\text { frequency } \\
f[\mathrm{~Hz}]\end{array}$ & $\begin{array}{l}\text { Natural } \\
\text { frequencies } \\
f[\mathrm{~Hz}]\end{array}$ & $\begin{array}{c}\operatorname{Max} q_{z}(t) \\
\quad[\mathrm{cm}]\end{array}$ & $\begin{array}{c}\text { Percentage } \\
\text { change } \\
q_{z}(t)\end{array}$ \\
\hline \multirow{3}{*}{4} & $8.92 \% *$ & \multirow{3}{*}{$1.7489 * *$} & $1.7489 *$ & 1.6737 & $0.00 \%$ \\
\hline & $10.15 \%$ & & 1.7487 & 1.6756 & $0.11 \%$ \\
\hline & $13.04 \%$ & & 1.7480 & 1.6761 & $0.14 \%$ \\
\hline \multirow{3}{*}{1} & $8.92 \% *$ & \multirow{3}{*}{1.7489} & $2.4112 *$ & 1.0700 & $0.00 \%$ \\
\hline & $10.15 \%$ & & 2.5713 & 0.9546 & $-10.79 \%$ \\
\hline & $13.04 \%$ & & 2.9103 & 0.8176 & $-23.59 \%$ \\
\hline \multirow{3}{*}{4} & $8.92 \% *$ & \multirow{3}{*}{$2.4112 * * *$} & $1.7489 *$ & 0.3153 & $0.00 \%$ \\
\hline & $10.15 \%$ & & 1.7487 & 0.3152 & $-0.03 \%$ \\
\hline & $13.04 \%$ & & 1.7480 & 0.3172 & $0.60 \%$ \\
\hline \multirow{3}{*}{1} & $8.92 \% *$ & \multirow{3}{*}{2.4112} & $2.4112 *$ & 0.9392 & $0.00 \%$ \\
\hline & $10.15 \%$ & & 2.5713 & 0.5802 & $-38.22 \%$ \\
\hline & $13.04 \%$ & & 2.9103 & 0.4542 & $-51.64 \%$ \\
\hline
\end{tabular}

* initial state; ** natural frequency corresponding to the first bending antisymmetric eigenform of the deck; *** natural frequency corresponding to the first bending eigenform of the cables No. 1 in $X Z$ plane.

grade line at the level of $\pm 0.00 \mathrm{~m}$. Two other efforts of cables No. 1 are respectively: $10.15 \%$ and $13.04 \%$. Tendon effort $\sigma_{i}$ in this case is defined as the ratio of static force $N_{\mathrm{i}}$ in cable to guaranteed breaking load $N_{\text {cr }}$, i.e., $\sigma_{\mathrm{i}}=N_{\mathrm{i}} / N_{\text {cr }}$ and it is expressed as a percentage. $N_{\mathrm{i}}$ is the static tension in the $i$-th cable with respect to the pre-tension of the cable and the deadweight of the whole structure.

Table 4 shows the maximum amplitudes obtained for each effort state of cables and the change of the natural frequencies of structure, corresponding to each effort state of cables.

On the basis of numerical analysis (see Figs. 5-8 and Table 4), it was found that the change in tension of cables number 1 slightly influences the change of displacement amplitude of the deck (node No. 4) by the excitation at the resonant frequency related to eigenforms of the deck, and at the efforts $13.04 \%$ the amplitudes decrease only by $0.14 \%$ as compared to the amplitudes of the initial state of the effort of the cables No. 1. The reduction of the amplitude of vibration in cable No. 1 (node No. 1) by $23.59 \%$ as compared to the amplitudes of the initial state of the effort of the cables was achieved. During the excitation at the resonant frequency equal to natural frequency of stay cables No. 1, i.e., $f=2.4112 \mathrm{~Hz}$, the change of cable tension (No. 1) significantly changes displacements amplitude. Upon the force change in cables No. 1 from the initial effort $8.92 \%$ to $10.15 \%$, it reduces the vibration amplitude by $38.22 \%$, and at efforts of $13.04 \%$ - by up to $51.64 \%$. It should be noted that, in the latter case, natural frequency of the cable changes significantly and hence the resonant state becomes detuned.

\subsection{THE CHANGE OF CABLES TENSION DURING THE HARMONIC EXCITATION}

In this section, the influence of the change of tension in cable No. 1 during the harmonic excitation on the amplitude of the vibrations of some nodes of the bridge was examined. Figure 9 presents influence of $\mathrm{C}_{1}$ cables tension change on vertical displacements amplitudes $q_{\mathrm{z}}$ of the deck for node No. 4. Figure 10 presents vertical displacements amplitudes of the $\mathrm{C}_{1}$ cable mid-span for node No. 1 at the resonant excitation. The excitation was performed with harmonic force, caused by three persons performing squats, with frequency equal to the natural frequency $\left(f_{\mathrm{c} 1} \approx 2.4112 \mathrm{~Hz}\right)$ corresponding to the first in-plane natural mode of vibrations of a stay cable No. 1. In this case, excitation includes 20 squats lasting for 8.3 seconds. Change of the tension in cables No. 1 was started in the 4th second and was completed after 4 seconds. The initial static effort in cables No. 1 was about $8.92 \%$ and after the change it was about $13.04 \%$. It can also be seen that the influence of $\mathrm{C}_{1}$ cable tension change significantly reduces (up to $75 \%$ ) amplitudes of forced resonance oscillations of $\mathrm{C}_{1}$ cable (cf. Fig. 10) while it does not affect the vibration displacements amplitude of the deck (cf. Fig. 9). 


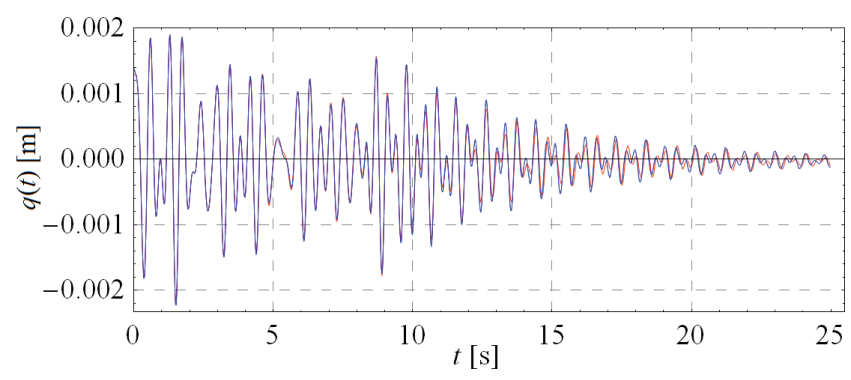

Fig. 9. Vertical displacements $q_{\mathrm{z}}(t)$ [m] for node No. 4 by harmonic excitation with frequency $f=2.4112 \mathrm{~Hz}$ for tension change in cables No. 1: - with cable tension change; - without cable tension change

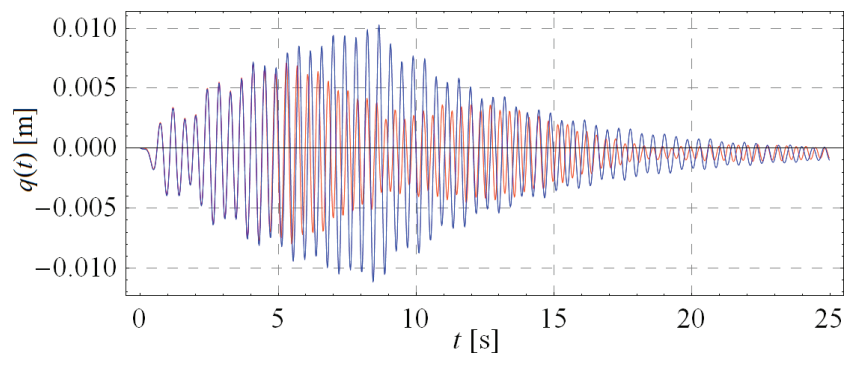

Fig. 10. Vertical displacements $q_{\mathrm{z}}(t)[\mathrm{m}]$ for node No. 1 by harmonic excitation with frequency $f=2.4112 \mathrm{~Hz}$ for tension change in cables No. 1: - with cable tension change; - without cable tension change

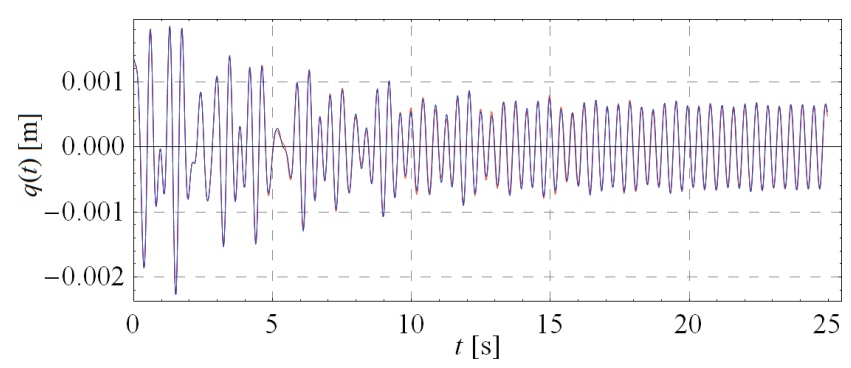

Fig. 11. Vertical displacements $q_{\mathrm{z}}(t)[\mathrm{m}]$ for node No. 4 by harmonic excitation with frequency $f=2.4112 \mathrm{~Hz}$ for tension change in cables No. 1: - with cable tension change; - without cable tension change

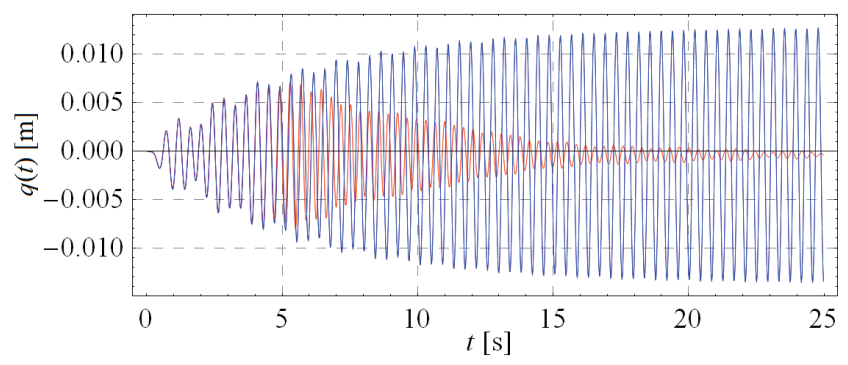

Fig. 12. Vertical displacements $q_{\mathrm{z}}(t)[\mathrm{m}]$ for node No. 1 by harmonic excitation with frequency $f=2.4112 \mathrm{~Hz}$ for tension change in cables No. 1: - with cable tension change; - without cable tension change
In another example, excitation includes 60 squats lasting for 25 seconds. The conditions for the excitation and the tension change in cables No. 1 are assumed as in the previous case. Figures 11 and 12 show the time histories of the vibration displacement, determined numerically using the system COSMOS/M. Also in this case, it has been proven that the influence of $\mathrm{C}_{1}$ cables tension change does not affect the vibration displacements amplitude of the deck (cf. Fig. 11), but significantly (up to 97\%) reduces amplitudes of forced resonance oscillations of $\mathrm{C}_{1}$ cable (cf. Fig. 12).

\section{SUMMARY AND CONCLUSIONS}

The main aim of the paper is to examine harmonically excited vibration of a cable-stayed footbridge while changing the static tension in chosen cables. The theoretical analysis has been carried out with the use of a 3D FEM numerical model. The numerical model of a footbridge closely corresponds to the real structure. Numerical research has been carried out under harmonic excitations, i.e., caused by squatting people. These harmonic excitations may occur in real footbridges [1]. For the purposes of a numerical solution of the FEM footbridge model, the parameters of several damping models have been determined. On the basis of numerical analysis, the mass damping model has been selected for further numerical analyses.

The paper has demonstrated, with the use of numerical analysis, the effectiveness of stay cable resonant vibration reduction in typical stayed-cable footbridges. It has been proven that the influence of $\mathrm{C}_{1}$ cable tension change (from the initial effort $8.92 \%$ to $13.04 \%$ ) significantly (up to $97 \%$ ) reduces amplitudes of forced resonance oscillations of $\mathrm{C}_{1}$ cable (cf. Fig. 12). An important result of the theoretical study is the proof that significant changes of the tension of selected stay cables do not affect the vibration displacements amplitude of the deck. It is a confirmation of the test results obtained in the author's own previous articles [2], [3] that it is possible to significantly change the tension of selected stay cables without causing considerable changes of eigenfrequencies corresponding to the eigenforms of the deck and pylon. Consequently, the above-mentioned tension change does not affect the vibration displacements amplitude of the deck. It must be highlighted that after such changes of static tensions in the cables that are enough to obtain a significant effect of the vibration reduction, the stresses in the cables have to remain much smaller than the permis- 
sible stresses, i.e., $13.04 \%<\sigma_{\text {perm. }}$. When the useful load is taken into account, permissible stress $\sigma_{\text {perm }}$ in the cables in cable-stayed bridges should be in the range from $30 \%$ to $40 \%$ of the characteristic resistance $f_{y k}$ of cables [4], [11].

Nowadays, passive and semi-active vibration dampers are commonly used in cable-stayed bridges and footbridges. There are also other methods of active reduction of cable vibration, which so far have been considered only theoretically and presented in scientific works [5]-[10]. The method presented in this paper can serve as an alternative to current methods of vibration reduction.

\section{REFERENCES}

[1] ŻóŁtowski K., Pedestrian on footbridge - loads and the response, Politechnika Gdańska, Gdańsk 2007.

[2] PAKos W., The experimental and theoretical analysis of active elimination of cables vibration in cable stayed footbridges, Unpublished doctoral dissertation, Politechnika Wrocławska, Wrocław, Poland, 2012, (in Polish).

[3] Pakos W., Wóscicki Z., Vibration control of a cable-stayed footbridge using the tension changes of cable, XXIII R-S-P seminar, Theoretical Foundation of Civil Engineering, Procedia Engineering, 2014, 91, 142-147.

[4] Pakos W., Wóscicki Z., Static and dynamic behavior of a selected cable-stayed footbridge with respect to change of the cable tension, Proc. Appl. Math. Mech., 2014, 14, 211-212, DOI 10.1002/pamm.201410093.

[5] ACHKIRE Y., Active Tendon Control of Cable Stayed Bridges, Doctoral dissertation, Active Structures Laboratory, Universite Libre de Bruxelles, Belgium, 1997.
[6] Preumont A., AchKire Y., Active damping of structures with guy cables, Journal of Guidance Control and Dynamics, 1997, 20(2), 320-326.

[7] Bossens F., Preumont A., Active tendon control of cable-stayed bridges: A large-scale demonstration, Earthquake Engineering and Structural Dynamics, 2001, 30, 961-979.

[8] Warnitchai P., Fujino Y., Pacheco B.M., Agret R., An experimental study on active tendon control of cable-stayed bridges, Earthquake Engineering \& Structural Dynamics, 1993, 22, 93-111.

[9] Fujino Y., Susumpow T., An Experimental Study on Active Control of In-Plane Cable Vibration by Axial Support Motion, Earthquake Engineering and Structural Dynamics, 1994, 23, 1283-1297.

[10] Susumpow T., Fujino Y., Active Control of Multimodal Cable Vibrations by Axial Support Motion, Journal of Engineering Mechanics, 1995, 121(9), 964-972.

[11] BiliszczuK J., Cable-stayed bridges. Design and implementation, Arkady, Warszawa 2005, (in Polish).

[12] BiliszCZUK J., BARCIK W., MAChELSKi CZ., ONYSYK J., Sadowski K., Pustelnik M., Design of steel footbridges, Dolnośląskie Wydawnictwo Edukacyjne, Wrocław 2009, (in Polish).

[13] KleIBer M., Technical Mechanics Volume XI. Computer Methods in Mechanics of Solid Bodies, Wydawnictwo Naukowe PWN, Warszawa 1995, (in Polish).

[14] Zienkiewicz O.C., Cheung Y.K., The Finite Element Method in Continuum and Structural Mechanics, ed. 1th. McGraw Hill, New York 1967.

[15] Bachmann H., Vibration Problems in Structures: Practical Guidelines, Birkhäuser Basel, Boston, Berlin 1995.

[16] Wóscicki Z., Grosel J., Structural dynamics, Wrocław University of Technology PRINTPAP Wrocław-Lódź 2011, from http://www.dbc.wroc.pl/publication/26131.

[17] PN-85/S-10030. Bridge structures. Loads 1985, (in Polish). 